\title{
PERFORMANCE CHARACTERISTICS OF ACTIVITIES IN PRIORITY 3 OF RURAL DEVELOPMENT PROGRAM 2014-2020
}

\author{
Antoni Mickiewicz ${ }^{1}$, Bartosz Mickiewicz ${ }^{2}$, Robert Jurczak ${ }^{3}$, \\ ${ }^{1}$ Higher School of Agribusiness in Lomza; \\ ${ }^{2}$ West Pomeranian University of Technology in Szczecin, Faculty of Economics; \\ ${ }^{3}$ State University of Applied Sciences in Konin
}

\begin{abstract}
The study covered five activities which, according to the European regulations, were included in Priority 3 of RDP 2014-2020. The aim of this priority is improvement in the organization of the food chain, promotion of animal welfare and risk management in agriculture. Most support instruments within the entire priority were pointed to processing and marketing of agricultural products $(42.8 \%)$ and to establishing of producer groups and organizations $(24.9 \%)$. The planned product indicators in the first case were set at the level of 1.5 thousand beneficiaries, in the second case at the level of 1.8 thousand groups, which will gather 36 thousand farmers. In general, 1619.0 million euros are intended for activities under Priority 3, including 1030.1 million euros from the European Agricultural Fund for Rural Development (EAFRD), or (12.0\%) of the indicative budget of the Rural Development Program (RDP), set at 13.5 billion euros, including 8.6 billion euros from the EAFRD.
\end{abstract}

Keywords: priority, activities, program, support.

JEL code: Q18

\section{Introduction}

The process of supporting the organization of the food chain, including the processing and marketing of agricultural products, animal welfare and risk management in agriculture is one of the most important tasks in the Rural Development Program. This phenomenon is important in the conditions of farm fragmentation, which is dominant in the Polish agriculture. The share of the small and medium agricultural producers in modern marketing channels is insignificant due to a small scale of production and the inability to adjust to quality requirements of the customers. The essence of an efficient functioning of the food chain is primarily in strengthening the agri-food processing sector by building integration links between farmers and processors. The farmers are expecting to ensure the certainty of sales and stability of prices of agricultural products. The access to the sale of agricultural products is more advantageous for producers with larger batches of goods, which are more uniform and meet the expectations of processors. For smaller producers, it is planned to organize farmers into groups or teams that will offer competitive products on the market. Due to the necessity to make farmers aware of the need for integration activities and the need for professionalization of the tasks undertaken by them in the fields of product quality and sales, it is essential to implement advisory and training activities in this sphere.

Risk prevention and risk management on farms is an important issue in Poland, especially due to the growing threats, which result from climate change. The intervention will cover farms affected by natural disasters, adverse climatic events and catastrophes. In addition, measures will be taken to protect the farms from adverse weather events in the future.

Generally speaking, in the development strategy for the ten-year period of the European Union CAP 2020 - it was assumed that future economic growth should be "smart", i.e. based on knowledge and innovation, "sustainable", i.e. in line with the needs of long-term development of the EU and "inclusive", i.e. beneficial for the whole society. Within the framework of rural development, the three strategic objectives related to competitiveness, natural resources and balanced territorial development should be pursued. The long-term goals were interpreted in terms of priorities, six of which were defined in the Regulation on rural development (CAP 2020, 2010). 
The goal of Polish policy in the field of food safety is a broadly understood protection of health and consumer interests. For this purpose, a number of legal standards were implemented in terms of not only the food hygiene control applicable to both farmers, producers, processors and sellers, but also the principles of correct labelling or packaging of food products. All these rules are to ensure compliance with the principle of transparency, that is, to guarantee the safety of food products at every stage of the production and distribution chain.

The main goal of the study was to analyse the Priority 3 of the RDP 2014-2020, which was primarily aimed at improving and creating the food chain, improving animal welfare and risk management in agriculture. Priority 3 is one of the six priorities included in the Rural Development Program. In their research work the authors wanted to characterize the five activities (focus areas) included in the Priority 3 in terms of requirements, expectations, scope of impact, costs and planned product indicators.

In the paper, there were used methods of induction in order to draw general conclusions from individual observations and synthesis with deduction for achievement of output of the known and already proven general theorems. The elaboration is mainly based on the European and national legislation, especially the Rural Development Program 2014-2020.

\section{Research results and discussion.}

In the European Union under the current financial perspective (2014-2020), it was assumed that measures (sub-measures) of the RDP should be viewed through the prism of priorities. The priorities have in some ways replaced the thematic axes in the previous rural development Program. The priorities allow for better identification of activities and more effective grouping them in the uniform focus areas. In turn, within the individual priorities, more detailed thematic areas have been distinguished, aiming at finding common features for a given group of activities.

Priority 3 aims to promote agricultural practices conducive to the creation of links between the agricultural sector and the processing of agri-food products and risk management. The implementation of this priority covers the whole range of financial instruments that aim at making agriculture and rural areas safe for the population and food production. At the base of this priority, there is integration of agricultural producers through creation of the food chain and development of the market for agricultural products. The basic goal is to support the competitiveness of the food sector, strengthen the position of producers and their closer link to the market. The process of integrating producers with the food chain will be carried out through quality systems, promotion on local markets and short supply cycles, producer groups and inter-branch organizations. Another goal is to introduce instruments to prevent and eliminate the effects of natural cadastres (EP and European Council Regulation, 2013).

One of the ways to achieve the goal is, for example, through groups of agricultural producers and producer organizations. Poland belongs to the group of countries whose agriculture is characterized by the lowest level of horizontal integration. Thus, agricultural producer groups and producer organizations are expected to play an increasingly important role in the food supply chain. The advantages of these groups are manifold. The groups improve the bargaining power of their members, create the added value, and allow to take advantage of economies of scale. In addition, the groups reduce the market risk, reduce transaction costs, provide access to resources and strengthen their competitive position through the product innovation and guarantee the food quality and safety. Financial support instruments aim to generate new groups and help them in 
their first period of operation. Groups implementing the commodity production should strive to eliminate intermediaries in agri-food trade and take their positions in the distribution of goods on the market.

In the division of financial instruments under Priority 3 , the most attention was paid to the processing and marketing of agricultural products (42.8\%) and the creation of producer groups and organizations $(24.9 \%)$. The planned product indicators in the first case were set at around 1.5 thousand beneficiaries, in the second case at the level of 1.8 thousand groups that will gather 36 thousand farmers. Potential recovery and preventive actions in replacement investments will support 4.8 thousand beneficiaries. Support for investments in the processing, marketing or development of agricultural products is intended to provide tangible or intangible investments for processing and marketing of agricultural products at the level of wholesale trade. The support is addressed mainly to micro, small and medium-sized enterprises operating in the processing sector or wholesale trade in agricultural products. Promotional support of local products will cover about 0.4 thousand manufacturers.

In turn, the action related to the quality system of agricultural products and foodstuffs will be implemented through two sub-measures, namely support for the new participants of the quality systems and carrying out the informational and promotional activities. The support is motivational and aims to facilitate production in the new conditions required by a specific quality system, which is to cover about 26 thousand producers (RDP, 2014).

\section{Characteristics of specific actions (sub actions) under Priority 3 1. Processing and marketing of agricultural products}

The processing and marketing of agricultural products plays an essential role in the food chain. The farmer is a supplier of raw materials, which in the further process require adaptation to the needs of consumers. For this reason, the help is granted for tangible or intangible investments regarding the processing and marketing at the level of wholesale trade in agricultural products. The help takes the form of reimbursement of a part of the eligible costs of the operation. The beneficiaries of this activity may be: a natural person; a legal person or an organizational unit without legal personality. Eligible costs include:

- costs of construction, modernization or reconstruction of production or storage buildings and structures constituting the infrastructure of processing plants, necessary to implement investments in the purchase of machinery and equipment or for infrastructure environmental protection;

- purchase costs (including installation) or leasing of machines or devices for processing, storing or preparing products for sale;

- costs of implementing the procedure of the certified quality management systems, fees for patents and licenses;

- general costs, i.e. preparation of technical documentation of the project, preparation of a business plan.

Each activity has specific eligibility conditions. In this sense, aid can be granted if certain requirements are met. First of all, an applicant is able to implement and maintain the planned project, which is verified on the basis of the analysis of economic data related to the current business activity and financial projections included in the business plan. Secondly, an applicant declares that after completion of the operation he will purchase at least $50 \%$ of the total amount 
of raw materials needed for production under long-term (at least 3-year) contracts concluded directly with farmers, producer groups or organizations, unions or associations of organizations of agricultural producers. Aid may be granted for the implementation of operations in plants that meet the applicable hygiene and sanitary, environmental protection and animal welfare standards. Investments assuming the increase of production capacity may be supported provided that the raw material base is documented and the disposal of the planned production is demonstrated. The measure supports investments in the processing sectors: milk, meat, fruit and vegetables, cereals and others (Regulation of the Ministry of Agriculture and Rural Development, 2015).

The rules for determining the selection criteria will include operations concerning, in particular:

- producer groups or producer organizations as well as unions or associations of producer organizations, and cooperatives;

- young farmers, i.e. farmers under 40 years of age;

- applicants purchasing raw materials for production on the basis of long-term contracts concluded directly with agricultural producers, at a level exceeding $50 \%$ of the total quantity of the purchased agricultural products;

- innovation, environmental protection, and counteraction of climate change.

The level of aid, which may amount to $50 \%$ of the investment eligible for support, is important.

The maximum amount of aid under the sub-measure granted during the Program implementation period to one beneficiary is 3 million zlotys, and in the case of associations of agricultural producer groups or associations of producer organizations, it amounts to 15 million zlotys. The minimum amount of aid granted for one operation is 100 thousand zlotys.

Table 1.

Number of applications submitted and amount applied for processing and marketing of agricultural products (2015)

\begin{tabular}{|l|c|c|}
\hline \multicolumn{1}{|c|}{ Provinces } & $\begin{array}{c}\text { Number of applications } \\
\text { submitted }\end{array}$ & $\begin{array}{c}\text { Amount applied for } \\
\text { (in thousands of zlotys) }\end{array}$ \\
\hline Lower Silesia & 30 & 61663.2 \\
\hline Kujawy-Pomerania & 61 & 92456.1 \\
\hline Lublin & 79 & 153423.6 \\
\hline Lubuskie & 24 & 51255.4 \\
\hline Lodz Province & 74 & 116213.9 \\
\hline Malopolska & 47 & 70544.4 \\
\hline Mazovia & 115 & 210352.2 \\
\hline Opole Province & 18 & 33913.1 \\
\hline Podkarpacie & 17 & 26059.1 \\
\hline Podlasie & 18 & 32673.6 \\
\hline Pomerania & 44 & 93505.4 \\
\hline Silesia & 45 & 86133.5 \\
\hline Swietokrzyskie & 32 & 50427.4 \\
\hline Warmia-Mazuria & 42 & 76260.8 \\
\hline Wielkopolska & 154 & 262952.7 \\
\hline West Pomerania & 34 & 72732.8 \\
\hline Total & 834 & 1439311.8 \\
\hline
\end{tabular}

Source: Management Information System of Agency for Restructuring and Modernisation of Agriculture

Based on the Regulation of Ministry of Agriculture and Rural Development of 2015, the Agency for Restructuring and Modernization of Agriculture collected applications of the future beneficiaries. Applications were submitted by 834 beneficiaries, the largest number in Wielkopolska (154), 
Mazovia (115), Lublin (79), and Kujawy-Pomerania (61) provinces. The four mentioned provinces, constituting $25 \%$ of all local governments, participate numerically at the level of $46 \%$. The claimed amount equals 1.4 billion zlotys.

Details are presented in Table 1.

\section{Restoration of agricultural production potential damaged by natural disasters and calamities and implementation of appropriate preventive measures}

As a result of deepening climate changes, agriculture is more and more often exposed to natural disasters in the form of hurricanes, hail, drought, excessive floods and other unpredictable phenomena. The size of a natural disaster cannot always be eliminated under usual insurance, therefore this measure was already introduced in the previous financial perspective. The action takes the form of material or non-material help allowing for the reproduction of agricultural production potential. The aid is intended to reconstruct those components of the farm's production potential that have been damaged or destroyed as a result of the above-mentioned events. The aid takes the form of reimbursement of a part of the eligible costs of the operation, the beneficiary being a farmer (RDP, 2014).

When thinking over the aid, it is important to determine the eligible costs. Eligible costs cover, among others: construction, reconstruction, renovation or modernization of buildings; purchase or construction of elements for technical infrastructure as well as costs usually linked to expenses, including costs of preparation of technical operational documentation of and purchase of livestock included in the basic herd. Aid is provided only if the investment is economically justified and it is not possible without the usage of public funds. The level of support is $80 \%$ of the eligible costs of an operation. The amount of aid may not exceed the value of damage caused by the relevant production potential on a holding. The maximum amount of aid granted to one beneficiary and per one agricultural holding may not exceed 300 thousand zlotys. The aid is granted for the operation with a planned amount of eligible costs of at least 20 thousand zlotys (RDP, 2014). Until the end of 2016, the executive regulations of the minister competent for agriculture did not appear, which did not allow the Agency for Restructuring and Modernization of Agriculture (ARMA) to start the call for applications.

\section{Investments in marketplaces or construction objects intended for promotion of local products}

According to the Rural Development Program (2014-2020), the construction and modernization of commercial infrastructure is aimed at creating places where farmers will be able to sell products produced on farms. Investments in marketplaces aim to shorten the food chain and increase the share of farmers in the added value. Construction or modernization of marketplaces is to facilitate the distribution of agricultural products. The action should contribute to better integration of the main producers into the food chain through quality schemes, promotion on local markets and short supply cycles implemented mainly by producer groups and producer organizations. Due to the nature of the operation, communes, administrative districts or their associations will be its beneficiaries. Therefore, eligible costs include the costs of construction, reconstruction or modernization of construction objects, purchase costs of materials and services for the implementation of operations, and general costs directly related to the preparation and implementation of operations (RDP, 2014). 
The aid takes the form of reimbursement of a part of eligible costs of the operation. The amount of the EAFRD aid may not exceed 1 million zlotys per beneficiary during the Program implementation. The aid will be granted if the operation is carried out in a city with no more than 200 thousand inhabitants, which will be coherent with the commune planning document or the local development strategy of the commune and will also be implemented on the property belonging to the applicant (RDP, 2014). Until the end of 2016, the executive regulations of the minister competent for agriculture did not appear, which did not allow ARMA to start the call for applications.

\section{Creation of producer groups and organisations in agricultural sector}

Instruments of financial support are launched to facilitate the creation of producer groups and organizations in the agricultural sector and are set out in the RDP 2014-2020. The state was given the opportunity to give priority to producer groups and organizations of high quality products covered by the action on the quality systems of agricultural products and foodstuffs. The above proceedings result from the limited financial resources. Groups must become profitable entities and therefore they should operate on the basis of business plans that are a condition for granting support (RDP, 2014).

The growing requirements of the consumers of agricultural raw materials and the need for horizontal integration is a harbinger of changes that encourage farmers to create groups and organizations of farmers' producers. There appear new social, economic or organizational arguments for generating new forms of cooperation.

From the point of view of agricultural producers, participation in the group of producers means for them stabilizing the sales of products, increasing the profitability of production. As part of a producer group or organization, there appears the possibility of joint planning and organizing the production so that it can ensure its appropriate size and quality.

Further benefits appear in the joint preparation of products for sale by storage and transportation. The groups should establish trade contacts and negotiate the terms of sale themselves and not through intermediaries. Members of the group must be aware that group action strengthens the position of agricultural producers in the food chain and is conducive to increasing their share in the added value. Cooperation with a group of producers is also beneficial for the consumers of the raw materials due to the possibility of ensuring regular supplies and adaptation of their size to the adequate and equal quality of the raw materials.

In this way, the food chain is shortened. The groups are part of a larger Program related to improving the competitiveness of agricultural producers through better integration with the agrifood chain, improvement of the quality systems and creation of the added value. Another feature of these groups is promotion of goods on local markets by producers' and inter-branch organizations. Additionally, groups of producers through the introduction of new solutions in the scope of production and marketing organization as well as production technologies can contribute to increasing the innovation of the agricultural sector. There is no doubt that the implementation of the measure should also be part of the climate and environmental objectives (RDP, 2014).

Preferences regarding access to support for groups and organizations are foreseen. The support will be granted to producers who grow plants for energy purposes or for technical use, and in the category of organic farming products. It is not envisaged to grant support for the creation of groups that carry out production in the field of live poultry, meat and edible offal. The creation of a 
group of agricultural producers should allow proper management of supply issues in the context of limiting the negative impact on the environment, including post-production waste. In addition, the funds should be intended for joint purchases, enabling team-based and thus more efficient use of machinery and equipment (RDP, 2014)

Financial assistance instruments have been changed. At present, support will be provided in the amount calculated as a percentage of the lump sum on the net income from the sale of products of the group. Revenues must be generated on the farms of its members and the amount will be analysed in particular years. The aid is granted for the first five years of the group's functioning from the date of its registration. An additional requirement is that the group should be a small or medium enterprise (SME).

The maximum amount of aid may amount to 100 thousand euros in the first year, the support is $10 \%$ of the amount, $8 \%$ in the second and it decreases by another $2 \%$ in subsequent years. The payment of the last installment of support will take place after confirming the correct implementation of the business plan, which is a new requirement in the current financial perspective. The business plan should include, in particular, the group's basic goals, a coherent concept of action and stages of group development. The business plan should describe the process of adapting the group to market requirements, the method of jointly launching goods to the market, and the preparation of the centralization of sales and delivery to wholesale customers. The new task is to establish common rules on production information with particular emphasis on data sets and availability of goods (RDP, 2014).

Assuming that groups are created solely and exclusively on the basis of financial support instruments, it is worth investigating the amount of assistance provided in the certain programming periods. In the first period of RDP (2004-2006), the EAFRD funds amounted to 139 million euros, which accounted for $05 \%$ of the total budget. Based on these funds, 100 groups were organized. In the next financial perspective, covering the 7-year programming period, 1.400 million euros was allocated for the creation of groups of agricultural producers, as a result of which 39 thousand groups were organized. In the period under discussion, the rate of group establishment varied. At first, the process proceeded with moderate interest. Only when the possibility of allocating part of the funds for investments (2012) and not only for administrative activity was allowed, it attracted more farmers willing to cooperate.

\section{Quality system of agricultural products and foodstuffs}

Among consumers, the expectations of food produced under quality systems are growing. They are based on specific and checked standards guaranteeing the product a unique quality. Joining the system is therefore an opportunity for the development of farms and strengthening cooperation in the food chain. Participation in such activities is associated with higher production costs, which is why it seems important to help all those interested in running this type of activity. The aim of the measure is to encourage agricultural producers to process and market the agricultural products with proven standards promoting animal welfare and risk management in agriculture, with particular emphasis on better integration of agricultural producers into the agri-food chain through the quality systems.

An additional goal is promotion on local markets and short supply cycles, support of producer groups and organizations and inter-branch organizations during this period. One should be aware that in order to distinguish and better protect the culinary heritage and the common achievements 
of generations, which are the best, and the unique traditional and regional products around the world, the European Union introduced a special system of certifying and marking these products. Thanks to the labelling of products, consumers have clear and reliable information about their exceptional quality and originality, and it gives the producers the opportunity to promote them and it enables protection against unfair competition and falsification of their products. Joining the quality system is connected with the farmer incurring additional costs resulting from the need to introduce necessary changes in the farm and subjecting it to the necessary controls in accordance with the specific system standards. Support is motivational and aims to facilitate production in the new conditions required by a specific quality system.

The measure - "quality systems for agricultural products and foodstuffs" will be implemented through two sub-measures:

1) support for new participants of quality systems that aims to increase farmers' participation in the EU and national quality systems;

2) support for informational and promotional activities including support for actions in the field of information and promotion of high-quality products undertaken by participants of quality systems, i.e. by promotional teams consisting of at least two producers.

Beneficiaries are economically active farmers. The amount of support is 2 thousand euros per year per farm for participation in the national and EU food quality systems. The aid takes the form of a refund within 3 years after joining the quality system.

Eligible costs include costs incurred in joining the quality system and an annual contribution for participation in the system. Eligible costs include expenses related to the control of compliance with the requirements of the system. The aid was granted to an applicant who manufactured agricultural products or foodstuffs for human consumption under the quality scheme, also in the previous financial perspective. The selection criteria take into account, in particular, the size of the land area on which an applicant produces production of high quality. Preferences in granting aid will apply to farms up to 5 ha, for which the fixed costs resulting from participation in the quality systems constitute a high financial burden. Support for carrying out informational and promotional activities aims at increasing the recognition of products covered by the quality systems. In turn, additional expenditures are required for recognition.

In Poland, there is still a low level of knowledge regarding the functioning of the EU and national quality systems under which high-quality products are produced. As a result, there is still a low demand for this type of products. The purpose of such support is to provide consumers with information about high-quality products and to pay attention to their advantages, which in turn should lead to an increase in demand. For producers, the possibility of obtaining additional financial aid means an incentive to increase the scale of production or to start to produce it. Higher demand for this type of production may positively affect the activation of rural residents and increase employment in these areas. The beneficiary is an entity called the "promotional team", created by at least two producers producing agricultural products or foodstuffs within the quality systems. The amount of support is $70 \%$ of the eligible costs for carrying out informational and promotional activities.

In 2016, the beneficiaries submitted 1186 applications, of which over 738 (62.2\%) were positively verified. The amount of support was set at 59 million zlotys. The data concerning the provinces are presented in Table 2 . 
Table 2.

\section{Number of applications submitted and amount of issued decisions in the field of production quality system (2016)}

\begin{tabular}{|c|c|c|c|}
\hline Provinces & $\begin{array}{l}\text { Number of } \\
\text { applications } \\
\text { submitted }\end{array}$ & $\begin{array}{l}\text { Quantity of } \\
\text { issued } \\
\text { decisions }\end{array}$ & $\begin{array}{c}\text { Amount of } \\
\text { decisions issued } \\
\text { (in thousands } \\
\text { of zlotys) }\end{array}$ \\
\hline Lower Silesia & 28 & 7 & 54.6 \\
\hline Kujawy-Pomerania & 62 & 38 & 260.8 \\
\hline Lublin & 72 & 34 & 290.7 \\
\hline Lubuskie & 19 & 4 & 32.2 \\
\hline Lodz Province & 64 & 40 & 304.5 \\
\hline Malopolska & 20 & 13 & 112.2 \\
\hline Mazovia & 458 & 350 & 2874.3 \\
\hline Opole Province & 8 & 2 & 18.0 \\
\hline Podkarpacie & 51 & 14 & 124.3 \\
\hline Podlasie & 34 & 19 & 165.7 \\
\hline Pomerania & 12 & 2 & 173 \\
\hline Silesia & 11 & 0 & 0.00 \\
\hline Swietokrzyskie & 115 & 87 & 722.8 \\
\hline Warmia-Mazuria & 97 & 47 & 326.7 \\
\hline Wielkopolska & 94 & 64 & 428.4 \\
\hline West Pomerania & 41 & 17 & 150.4 \\
\hline Total & 1186 & 738 & 5882.9 \\
\hline
\end{tabular}

Most beneficiaries submitted their applications in Mazovia, (458) Swietokrzyskie (115) and Warmia-Masuria (97) provinces. Source: Management Information System of Agency for Restructuring and Modernisation of Agriculture

\section{Conclusions}

1) The European Union has identified six priorities for rural development. They were divided into 18 focus areas in order to better and more precisely define each priority and to facilitate the programming process.

2) The Rural Development Program sought to identify the specific policy objectives for each thematic area. The discussed Priority 3 related to the creation of the food chain and risk management was based on five activities (sub-measures). They were connected by the main objective linked thematically to the areas of impact.

3) By the end of 2016, two activities were launched in the amount of 1444.3 million zlotys, which, taking into account the exchange rate of EUR to PLN at 4.32 (according to the European Central Bank), equals 334.3 million euros, or $20.4 \%$ of the indicative budget within the discussed priority.

4) Incomplete launch of all activities was partly due to the process of settling the European funds. The system of financing the EU projects requires that the national budget first put out the money, and only after the end of the activity makes the settlement.

5) Every year, the European Union sets annual (partial) budgets, which together should take the shape of a 7-year financial perspective. The late launching of the actions specified in the Program for the years 2014-2020 resulted from the difficulty of settling the measures contained in the Multiannual Financial Framework 2007-2013 (the $R+2$ rule) and reorganization factors in the agricultural sector and paying agencies. 


\section{BIBLIOGRAPHY}

1. CAP 2020: Meet the Future Challenges of Food-related Natural Resources and Territorial Aspects. European Commission (2010), Brussels, p. 481

2. Program Rozwoju Obszarow Wiejskich w 2015 (Rural Development Program for 2015). Ministry of Agriculture and Rural Development (2015). Warsaw, p. 265

3. Regulation EP (EC) No 1305/2013 of 17 December 2013 on support for rural development by the European Agricultural Fund for Rural Development (EAFRD) repealing Regulation of the Council of the European Union No 1698/2005. (2013). Brussels, p. 161

4. Regulation of the European Parliament and of the Council of Europe (EU) No R 1151/2012 of 21 November 2012 on quality schemes for agricultural products and foodstuffs. (2013). Brussels, p. 161

5. Regulation of the Minister of Agriculture and Rural Development of 5 October 2015 on detailed conditions and procedure for granting and payment of financial aid under the sub-measure "Support for investment in agricultural products, their processing or development" covered by the Rural Development Program for 2014-2020. Ministry of Agriculture and Rural Development (2015). Warsaw, p. 321

6. Regulation of the Minister of Agriculture and Rural Development of 7 July 2016 on detailed conditions and procedure for granting and payment of financial aid under the sub-measure "Support for information and promotion activities carried out by producer groups on the internal market" covered by the Rural Development Program for 2014- 2020. Ministry of Agriculture and Rural Development (2016). Warsaw, p. 194 